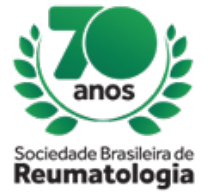

\title{
LUPUS NEPHRITIS REFRACTORY IN MALE PATIENT
}

Letícia Lopes Coimbra (Hospital Geral de Palmas. Universiodade Federal do Tocantins., Palmas, TO, Brasil), Andressa Vieira Ruiz (Hospital Geral de Palmas., Palmas, TO, Brasil), Ana Caroline Martins Borges (Hospital Geral de Palmas., Palmas, TO, Brasil), Allethéa Robertha Souza e Silva (Hospital Geral de Palmas., Palmas, TO, Brasil), Maria Eduarda Guimarães Leal (Hospital Geral de Palmas., Palmas, TO, Brasil), Danilo Garcia Ruiz (Hospital Geral de Palmas., Palmas, TO, Brasil), Daniela Maria Edilma Japiassú Custódio (Hospital Geral de Palmas., Palmas, TO, Brasil), Paulo Geovanny Pedreira (Hospital Geral de Palmas., Palmas, TO, Brasil), Rafaela Alen Costa Freire (Hospital Geral de Palmas., Palmas, TO, Brasil), Paola Bottin Madrid (Hospital Geral de Palmas., Palmas, TO, Brasil), Hugo de Carlos Maciel Rossoni (Hospital Geral de Palmas., Palmas, TO, Brasil)

\section{BACKGROUND}

Kidney involvement in lupus occurs in about $60 \%$ of patients, and glomerular abnormalities demonstrated in renal biopsy determine most of the signs and symptoms of lupus nephritis, in addition to guiding treatment. We present the uncommon case of male with lupus with refractory renal involvement and difficult to control.

\section{CASE REPORT}

Patient T.S.L, 19 years old, male, hospitalized due to anasarca, arthritis of wrists, oliguria, beginning 60 days ago. Made use of benzathine penicillin to treat syphilis due to 1/32 VDRL reagent. At physical examination, the patient was in regular general condition, with diffuse petechiae in the body, periorbital edema, mild malar rash, lesion on hard palate, decreased pulmonary auscultation on bases, submacetic abdomen on percussion, ascites. Tests performed: Creatinine: 2,3, urea: 132, hemoglobin: 8 , ultrasound of the abdomen with moderate ascites and visualized discrete bilateral pleural effusion. Echocardiogram with discrete pericardial effusion. Treponema IgM and non-reactive IgG. Diagnosis of systemic lupus erythematosus with the following criteria was performed: FAN homogeneous nuclear standard reagent titre 1: 640, native ANTI-DNA: reagent 1/80, ANTI-SM: reagent (480), polyarthritis, Anti-Cardiolipin: IgM: reagent 41.4) and IgG: reagent (45.5), serositis, malar rash, complement consumption, oral ulcers, antiB2 glycoprotein $1 \mathrm{IgM}$ : reagent and nephrite with 24-hour proteinuria: 5,565mg. Performed renal biopsy: diffuse proliferative Lupus Nephritis - grade IV. During hospitalization, the patient developed worsening renal function with a significant increase of nitrogenous slags, requiring serial hemodialysis. Pulse therapy with methylprednisolone $1 \mathrm{~g} /$ day for 3 consecutive days and cyclophosphamide $1 \mathrm{~g} /$ month, in addition to hydroxychloroquine $400 \mathrm{mg}$ and prednisone $1 \mathrm{mg} / \mathrm{kg} /$ day for 6 weeks, followed by gradual weaning. After the second dose of cyclophosphamide, the patient evolved with improved clinical status, increased diuresis, and improved renal function requiring no further hemodialysis. He was discharged from hospital and maintained pulse therapy with monthly cyclophosphamide. After 6 doses of the immunosuppressant, despite an improvement in renal function, patients present worsening of proteinuria $24 \mathrm{hrs}: 10,000 \mathrm{mg}$, being classified as refractory lupus nephritis.

\section{CONCLUSION}

In the present report, the refractoriness of the disease was concluded even though adequate treatment, demonstrated through the persistence and increase of proteinuria, was carried out. About $10 \%$ to $29 \%$ of patients develop into chronic kidney disease, even with adequate treatment. The literature reports mainly from patients with the same profile described in this case, and relates the aggressive condition of the disease to glomerular inflammatory events. In these cases the therapy instituted by another immunosuppressive drug should be changed. 